\title{
PhYSICAL aCTIVITY IN THE WATER aCCOMPANIED BY MUSIC
}

\section{Anna Kwaśna, Stefan Szczepan, Aleksandra Spirydowicz, Krystyna Zatoń}

Department of Swimming, University School of Physical Education in Wroclaw, Poland

\section{ABSTRACT}

Introduction: Music motivates, relaxes and stimulates action and is one factor which enhances the pleasure that people feel from a given movement. Thus, from a psychophysical point of view, listening to music is an important aspect in sport and recreation. With this in mind, the aim of the study was to determine any changes in the participants' psychophysical sphere which resulted from listening to music while swimming. The psychophysical sphere was expressed in relation to the Borg RPE scale (Rating of Perceived Exertion) as well as the Rejeski and Gauvin Exercise-Induced Feeling Inventory (EFI) scale of emotional states.

Material and methods: The participants in the study were not professional swimmers $(n=10)$. The experiment consisted of two trials in which participants performed the Swimming Cooper test. During the first trial there was no music transmitted while in the second trial specifically selected music was played as the participants swam.

Results: An ANOVA variance analysis $(\alpha=0.05)$ showed statistically significant differences in the RPE scale $(p=0.04)$ and across all sensations on the EFI scale $(p=0.001, p=0.001, p=0.001, p=0.001)$.

Conclusions: Listening to music while swimming has a significant impact on the human psychophysical sphere and is expressed by a perceived exertion scale and the scale of emotional states.

Respondents paid less attention to the discomfort of physical exertion associated with exercise while listening to music. The rating of their emotional states, including positive engagement, revitalization and tranquility considerably increased though the physical exhaustion measures were significantly lower.

Key words: music, values, motivation, perceived exertion, states of feelings, swimming

\section{ARTICLE INFO}

PolHypRes 2016 Vol. 57 Issue 4 pp. 55 - 64

ISSN: 1734-7009 elSSN: 2084-0535

DOI: $10.1515 / p h r-2016-0026$

Pages: 10 , figures: 0 , tables: 0

page www of the periodical: www.phr.net.pl

Publisher

Polish Hyperbaric Medicine and Technology Society
Original article

Submission date: $24.04 .2016 r$

Acceptance for print: 02.09.2016r. 


\section{INTRODUCTION}

Physical activity is an important factor impacting on human health. It stimulates the skeletal, muscular, cardio-respiratory and nervous systems and also impacts on one's mental condition [1]. In particular, this applies to physical activity in an aquatic environment. Exercising in water does not strain the joints (due to the buoyancy force), while the horizontal swimming position has a positive influence on the functionality of the circulatory system [2]. Additionally, with the ability to swim, a person can pursue a variety of timeless values that are indispensable in the modern world.

Physical activity in the water allows a person to actualize and internalize the values resulting from the learned swimming skills. The most important are utilitarian, vital, aesthetic, social, recreational and agonistic values. The utilitarian value stems from the ability to move in an aquatic environment. This ability allows, among other things, the individual to take care of themselves in situations which prove to be life threatening or detrimental to one's health; such situations can happen with the overestimation of one's skills in the water.

To be able to implement the utilitarian value, it is indispensable to equip oneself with the ability to swim [3]. Vital values relate behaviors which promote health, prevention and rehabilitation [4]. The health dimension of the body is expressed in the form of recuperative, preventive and creative actions. The curative factor, influencing health is not only the movement itself, but the physical and chemical interaction of the water on the body [5].

Aesthetic values morphologically concern the shaping of a beautiful body. During swimming, the hydrodynamic drag force activates the majority of muscles and improves one's figure [6]. Aesthetics, with regard to kinetics is the precision with which the movement is completed [7].

In particular, aesthetic values are visible in the aquatic environment during synchronized swimming and diving. These sports require a unique aesthetic body form and precise movements $[8,9]$. Social values manifest themselves when dealing with and socializing with other people. A recreational value is realized during leisure diving, sailing, kayaking and pedal boating [10].

The agonistic value refers to the degree to which competitive needs are fulfilled, which in turn can be observed during sports competitions $[11,12]$.

The values presented, which derive from physical activity in the aquatic environment, make it possible to achieve one's health and recreation objectives and develop the potential of human motor skills. From this perspective, the ability to swim is both a biological and social necessity.

Currently, in developed societies there is a domination of stagnation over motion [13]. Therefore, the search for methods that drive positive changes in human behavior, manifested in an active leisure time in the aquatic environment, is of prime importance. To date, most of the activities associated with this dilemma have focused on improving movement techniques to enhance the efficiency of swimming $[14,15]$.

However, there are opinions about the necessity of selecting methods by which water based activities will become more attractive. With increased attraction, the chance of more frequent physical activity increases also, which positively affects human health. Considering the fact that repeated exercises in the water can become monotonous, necessity becomes a factor which too increases its attractiveness $[16,17]$.

For this purpose, one such method is the use of music. Years ago, music therapy was identified as an effective means for the treatment of depression and stress reduction [18]. However, its properties have begun to be appreciated in many other domains of life: especially physical activity. Due to advances in technology, music is able to be successfully implemented into sport and physical recreation $[19,20]$.

Numerous studies have confirmed that listening to music has a positive effect on the psychological, psychophysical and ergogenic sphere [21,22]. The psychological sphere refers to the changes in mood and behavior. Music is able to both stimulate and relax $[23,24,17]$. Furthermore, music also causes a reduction in the level of 'starting stress' prior to commencing a movement [21]. Music enhances the level of pleasure that derives from completing a movement, especially when conducting more monotonous and repetitive motor actions [25]. The term 'psychophysical sphere' refers to the reduction in perceived levels of exertion [26]. The ergogenic sphere refers to the stimulation to move, an improvement in physical function and an increase of endurance and efficiency $[27,28]$.

From a psycho-physical perspective, listening to music has become an important element in sport and recreation. For some time, music has been a popular choice for those partaking in a range of physical activities, i.e. running [21,29], rowing [30], cycling [31]. In spite of the fact that music is commonly used for exercises on land, it is only recently, with the emergence of underwater MP3 players, that music has become more popular with activities in the aquatic environment. Therefore, it is now possible for swimmers to experience the positive values associated with listening to music while undertaking physical activity in the water.

Considering the many benefits of listening to music and the manner in which it enhances one's psychophysical sphere, this study was undertaken in order to investigate and objectively verify the aforementioned benefits.

In turn, the aim of the study was to determine the changes in the psychophysical sphere which occur as a result of listening to music while swimming. The psychophysical sphere was expressed using the Borg's scale which measures perceived exertion (RPE) [32] as well as the Rejeski Gauvin (EFI) scale of emotional states [33].

It was assumed that music played during swimming would cause changes in the psychophysical sphere of a swimmer. For the purpose of verification of the hypothesis the following research question was formulated: How does the psychophysical sphere of a swimmer change as a result of listening to music while swimming?

\section{MATERIAL AND METHODS}

Participants 
The participants of the study were ten healthy, physically active people; 5 men and 5 women aged $29 \pm$ 12.08 (years), with a body height $1.74 \pm 0.01(\mathrm{~cm})$, and body mass $67.4 \pm 12.0(\mathrm{~kg})$. The small size of the group was due to the pilot nature of the study. The participants were not professional swimmers. They were people who practiced swimming twice a week for one hour. However, the amount of physical activity in water for the participants was limited to one hour of swimming once a week.

All subjects were informed about the nature of the experiment and its circumstances. The participants gave written consent to participate in the study. An ethics committee approved the testing.

Procedure

Before the main experiment, a list of music tracks was prepared; each person selecting their own personal choices of motivating music that was intended to stimulate them to complete the specific actions and behaviors. Motivation is the systems needs and values, which define both the direction and the degree of the individuals' involvement when endeavoring to complete an action [34]. The list of songs was added to the memory of a waterproof MP3 player - a Dolphin Touch (NU, Taiwan).

The main experiment took place in a 25 -meter swimming pool. It was composed of two exercise tests. The trials were preceded by a 5 minute warm-up in the water. In the research the breaststroke swimming technique was used. In each trial, participants performed a Swimming Cooper Test.

This involved swimming using any chosen stroke for as long a distance as possible within 12 minutes. Distance is measured to an accuracy of 25 meters [35]. During the first trial the music was not played while performing the test. In the second trial, the individually selected music was played during swimming. The aim was that music will produce changes in the psychophysical sphere of the participants. The psychophysical sphere was expressed using the RPE and the EFI scale.

To reduce the effects of fatigue, subjects performed all trials with a one-week rest between each test. Between the two trials the subjects did not participate in any other forms of physical activity. Additionally, in order to minimalize the impact of circadian rhythms, the participants always performed at the same time of day [36].

\section{Measurements}

The subjective assessment of perceived exertion was measured using the Borg's scale (RPE). Borg's scale consists of 15 levels beginning with the number 6 , which corresponds to the state of rest, and heart rate 60 / min and ending with the number 20 , which corresponds to the maximum effort and heart rate of $200 / \mathrm{min}$ [32]. The subjects evaluated the perceived effort after each test. For the further statistical analysis, the scale values obtained under the two conditions were used.

Emotional states were measured using the Gauvin's and Rejeski's scale (EFI) [33]. The Gauvin's and Rejeski's scale measures four states: a) positive engagement, b) revitalization, c) tranquility, d) physical exhaustion. In the assessment of positive engagement, terms such as; enthusiastic, happy and with positive attitude were used. In the assessment of revitalization the following terms were used; refreshed, energetic and lively.

In the assessment of tranquility the use of terms such us; mentally calm, relaxed and physically composed were salient. In the assessment of physical exhaustion the following terms were used; physical exhaustion, physical fatigue and exertion. Each state was evaluated on a scale from 0 (don't feel) to 4 (strongly feel). The respondents evaluated their states of feelings immediately before and after each test. For further statistical analysis the differences in the values obtained in the two conditions were used.

\section{Statistical analysis}

Statistical analyses were carried out using the program; Statistica 9.0 (StatSoft, USA). To determine the differences in the variables (Borg's scale and the Gauvin's and Rejeski's scale) in the two conditions - with and without music, a univariate analysis of variables (ANOVA) was used. Testing was performed at a statistical significance level of $\alpha=0.05$.

\section{RESULTS}

The ANOVA Analysis of variation demonstrated a statistically significant difference in both the Borg's scale (RPE) and the Gauvin's and Rejeski's scale (EFI). This shows that the indicated variables have a diagnostic value in the context of comparing the two conditions (with and without music).

Subjective rating of the perceived exertion Borg's scale (RPE)

The average value of the RPE scale for the trial without music was: $14.50 ; \pm 2.01$, with music: $12.50 ; \pm$ 1.75. A univariate analysis of variation (ANOVA) showed a statistically significant difference in the RPE scale for the two music conditions ( $p=0.04, \leq 0.05)$.

Emotional states - Gauvin's and Rejeski's scale

\section{a) Positive engagement}

The average value of the positive engagement for the trial without music was: $-1.40 ; \pm 0.80$, with music: $2.10 ; \pm 0.94$. A univariate analysis of variation (ANOVA) showed a statistically significant difference in the perception of positive engagement for the two music conditions $(\mathrm{p}=0.001 \leq 0.05)$.

\section{b) Revitalization}

The average value of the feeling of revitalization for the test without music was: $\bar{x}-2.70 ; \pm 2.76$, while with music it was: $\bar{x}-1.70 ; \pm 1.10$. A univariate analysis of variation (ANOVA) showed a statistically significant difference in the perception of the revitalization for the two conditions ( $p=0.001, \leq 0.05)$.

\section{c) Tranquility}

The average value of the feeling of tranquility for the test without music was: $\bar{x}-1.30 ; \pm 1.68$, with music: $\bar{x} 3.70 ; \pm 1.79$. A univariate analysis of variation 
(ANOVA) showed a statistically significant difference in the perception of tranquility for the two music conditions $(p=0.001, \leq 0.05)$.

\section{d) Fatigue}

The average value of the feeling of fatigue without music was: $\bar{x} 7.10$; \pm 2.02 , with music: $\bar{x} 3.90$; \pm 1.22. A univariate analysis of variation (ANOVA) showed a statistically significant difference in the perception of fatigue for the two conditions $(\mathrm{p}=0.001, \leq 0.05)$.

\section{DisCUSSION}

Music, which so far has been identified with relaxation therapy and stress reduction, due to technological progress has now been transferred into the area of sport and recreation. Currently, athletes listen to music during athletic, rowing or cycling training $[30,31,29]$. Due to the development of waterproof MP3 players it is possible to benefit from listening to music also while swimming [20].

The aim of this study was to determine the changes in the psychophysical sphere resulting from listening to music while swimming. In the research the psychophysical sphere was expressed by the use of Borg's Rating of Perceived Exertion Scale (RPE) [32] and the Exercise-Induced Feeling Inventory (EFI) Scale of Rejeski and Gauvin [33]. The results revealed the potential benefits of listening to music while swimming. Music has a significant impact on the psychophysical sphere of swimmers, which is expressed by the scale of perceived exertion and the scale of emotional states.

The RPE scale is used to assess perceived exercise intensity [32]. In the present experiment, with the use of the RPE scale, the participants rated their perceived exertion much lower while swimming with music than during the trial without music $(\mathrm{p}=0.04$, $\leq 0.05$ ). Presented results are consistent with the Borg study [32]. It assumed that environmental factors, such as music, temperature, and social impact distract from the exertion, resulting in too high or too low rating on the scale. Also Johnson \& Siegel [37] used the RPE scale among people who focused their attention on music while exercising.

Their perception of exertion was also lower than when they focused only on internal sources of information. Furthermore, Karageorghis \& Terry [38] also recognized that listening to music enables a detachment from unpleasant feelings such as pain and fatigue and also lowers one's perception of exertion. Similar conclusions were reached by Terry et al., [29], who studied professional triathletes. During intense training, the contenders had lower RPE while listening to music, which also led to an increase in their endurance levels. A decrease in the perception of exertion, as measured by the RPE scale, is only one of many benefits for athletes which derives from listening to music.

Another added value of music is its impact on changes to one's emotional state. The results of the study showed a difference in the EFI scale for the four emotional states while swimming under two musical conditions. Listening to music significantly contributed to an increase in the respondents' positive engagement $(\mathrm{p}=0.001 \leq 0.05)$, revitalization $(\mathrm{p}=0.001, \leq 0.05)$ and tranquility $(p=0.001 \leq 0.05)$. However, the perception of physical exertion decreased significantly $(p=0.001$ $\leq 0.05$ ). This confirms the study of Rejeski et al., [39], in which music provided a distraction from the discomfort associated with exercise. Similar conclusions were reached by Karageorghis \& Terry [38], who observed in the participants an increase in positive mood and a corresponding reduction in negative feelings as well as increased relaxation of the body and a positive mental state.

In the present study, the value of listening to music was shown to be justified during both professional and recreational swimming training, which provides a contextual foundation for the submission and validity of the research. The results of the research have shown that music plays an important role in distracting swimmers from thinking about the pain and fatigue that occurs during training. Listening to music increases positive emotional reactions which promotes satisfaction. Music also affects positive engagement in the exercise performed. It causes psychological revitalization of the body. It soothes the physically and mentally exerted body and reduces the feeling of physical exhaustion.

It decreases the feeling of fatigue, which typically appears after multiple repeated actions, like for example during prolonged swimming training. The values revealed that listening to music while swimming helps in the achievement of various objectives related to health, recreation as well as the development of the human motor potential. Music is a means that can be used to enhance the attractiveness of physical activity in the water.

Numerous authors have also pointed to other values resulting from listening to music. These include activation before exertion and increased efficiency $[30,25]$. The positive impact of music on motor skills acquisition was also confirmed [38], although it appears that listening to music can disrupt human multisensory perception in the water. However, it has been shown, that there are still many uncertainties regarding the mechanisms of music that impact on the human body. Experiments in this direction require's complex neurophysiological study.

\section{Conclusions}

The conclusions regarding the results of the presented pilot research are of a contributing character. They constitute a forecast of further works conducted in this direction as well as a hypothesis for further experiments towards an explanation of the effect of listening to music while swimming on changes in the psychophysical sphere of a swimmer.

1. Listening to music while performing swimming motor tasks significantly impacts on the psychophysical sphere of a human, which is expressed by the scale of perceived exertion as well as the scale of emotional states.

2. Music has a considerable impact on the subjective rating of perceived exertion. The participants who listened to music while swimming, paid less attention to their exertion levels and the accompanying discomfort.

3. Music has a significant impact on emotional states. Ratings of emotional states, including positive engagement, revitalization and tranquility has increased, though the physical exhaustion decreased while swimming with music. Listening to music causes positive associations that distract one from their level of 
exertion and reduce the sense of unpleasant stimuli associated with discomfort.

4. The use of music during both professional and recreational swimming training in order to increase the attractiveness and satisfaction of exercises is justified. Listening to music while swimming makes training more enjoyable and less monotonous, which in turn makes one more likely to undertake it.

\section{BIBLIOGRAPHY}

1. Biddle S.J.H., Fox K.R., Boutcher S.H. Physical activity and psychological well-being. Washington D.C.: Taylor \& Francis. 2000;

2. Meyer K., Bucking J. Exercise in heart failure: Should aqua therapy and swimming be allowed? Medicine and science in sports and exercise. 2004, 36, 2017-2023

3. Stallman K.R. Reflections on philosophical issues on lifesaving. S. Avramidis (Ed.), Handbook on safety and lifesaving. Piraeus, Greece: European Lifeguard Academy. 2008, 444-450;

4. Prins J., Cutner D. Aquatic therapy in the rehabilitation of athletic injuries. Clinics in sports medicine. 1999, 18(2), 447-61;

5. Davis B., Harrison R. (1998). Hydrotherapy in Practice. New York: Churchill Livingstone;

6. Walsh M. Hydrotherapy: The Use of Water as a Therapeutic Agent. In S. Michlovitz (Ed.), Thermal Agents in Rehabilitation. (3rd Ed.). F.A. Philadelphia, PA: Davis Co. 1995;

7. Lee T., Swinnen S., Serrien J. Cognitive effort and motor learning. Quest. 1994, 46, 328-344;

8. Chu D.A. Athletic training issues in synchronized swimming. Clinics in Sports Medicine. 1999, 18(2) 437-445;

9. Driscoll H., Gaviria S., Goodwill S. Analysing Splash in Competitive Diving. Procedia Engineering. 2014, 72, 26-31;

10. Zatoń K., Kwaśna A. Wartości rekreacyjne, jako aspekt aktywności ruchowej w wodzie/Recreational values of water exercise. Rozprawy naukowe AWF we Wrocławiu, 2011, 34, 176-180;

11. Neil R., Hanton, S., Mellalieu S.D., Fletcher D. Competition stress and emotions in sport performers: The role of further appraisals. Psychology of Sport and Exercise. 2011, 12, 4, 460-470;

12. Kosiewicz J. Sport and Social Deviations - a Prognostic Attitude. Physical Culture and Sport Studies and Research. 2014, 62 (1), 63-72;

13. Hanson M.A., Gluckman P.D. Developmental origins of health and disease - Global public health implications. Best Practice \& Research Clinical Obstetrics \& Gynaecology. 2015, 29, (1) 24-31;

14. Zatoń K., Szczepan S., Kazimirów R., Rejman M. Advisability on the shift from standard front crawl swimming technique to the "kayaking" and "loping" variants. Human Movement. 2012, 13(3) 225-235;

15. Barbosa T.M., Keskinen K.L., Fernandes R., Colaco P., Lima A.B., Vilas-Boas J.P. Energy cost and intracyclic variation of the velocity of the centre of mass in butterfly stroke. European Journal of Applied Physiology. 2005, 93, 519-523;

16. Hume K.M., Crossman J. Musical reinforcement of practice behaviors among competitive swimmers. Journal of applied behavior analysis. 1992, 725, 665-670;

17. Szczepan S., Kulmatycki L. Psychophysical motivational effects of music on competitive swimming. Baltic Journal of Health and Physical Activity. 2012, 4, 197-204

18. Maler T. Musik und ekstate in einer ostafikanischen medizinmann praxis/Music and ecstasy in east african medicine man practice. H. Willms (ed.), Musik und Entspannung. Stuttgart, New York: Fischer. 1977;

19. Tate A.R., Gennings C., Hoffman R.A., Strittmatter A.P., Retchin S.M. Effects of bone-conducted music on swimming performance. Journal of strength and conditioning research. 2012, 26(4), 982-988;

20. Karageorghis C.I., Hutchinson J.C., Jones L., Farmer H.L., Ayhan M.S., Wilson R.C., Rance J., Hepworth Ch.J., Bailey S.G. Psychological, psychophysical, and ergogenic effects of music in swimming. Psychology of Sport and Exercise. 2013, 14, 560-568;

21. Simpson S.D., Karageorghis C.I. The effects of synchronous music on 400-m sprint performance. Journal of Sports Sciences. 2006, 24, 10951102;

22. Karageorghis C.I., Mouzourides D., Priest D.L., Sasso T., Morrish D., Walley C. Psychophysical and ergogenic effects of synchronous music during treadmill walking. Journal of Sport \& Exercise Psychology. 2009, 31, 18-36;

23. Karageorghis C.I., Terry P.C., Lane A.M. Development and validation of an instrument to assess the motivational qualities of music in exercise and sport: The Brunel Music Rating Inventory. Journal of Sports Sciences. 1999, 17, 713-724;

24. Hewston R., Lane A.M., Karageorghis C.I., Nevill A.M. The effectiveness of music as a strategy to regulate mood. Journal of Sports Sciences. 2005. 22, 181-182;

25. Karageorghis C., Priest D.L. Music in sport and exercise: An update on research and application. Sport Journal. 2008. 11, 1-7;

26. Tenenbaum G., Lidor R., Lavyan N., Morrow K., Tonnel S., Gershgoren A. The effect of music type on running perseverance and coping with effort sensations. Psychology of Sport and Exercise. 2004, 5, 89-109;

27. Karageorghis C.I., Jones L., Low D. Relationship between exercise heart rate and music tempo preference. Research Quarterly for Exercise and Sport. 2006, 26, 240-250;

28. Terry P.C., Karageorghis C.I. Music in sport and exercise. T. Morris, P.C. Terry (Eds.), The new sport and exercise psychology companion. Morgantown, WV: Fitness Information Technology. 359-380, 2011;

29. Terry P.C., Karageorghis C.I., Mecozzi Saha A., D'Auria S. Effects of synchronous music on treadmill running among elite triathletes. Journal of Science and Medicine in Sport. 2012, 15, 52-57;

30. Rendi M., Szabo A., Szabo T. Performance enhancement with music in rowing sprint. The Sport Psychologist. 2008, 22, 175-182;

31. Nakamura P.M., Pereira G., Papini C.B., Nakamura F.Y., Kokubun E. Effects of preferred and nonpreferred music on continuous cycling exercise performance. Perceptual and motor skills. 2010, 110, 257-264

32. Borg G. Borg's Perceived Exertion and Pain Scales. Champaign, IL: Human Kinetics. 1998;

33. Gauvin L., Rejeski W.J. The Exercise-Induced Feeling Inventory: Development and initial validation. Journal of Sport \& Exercise Psychology. 1993, 15, 403-423;

34. Richard R., Deci E.L. Intrinsic and Extrinsic Motivations: Classic Definitions and New Directions. Contemporary Educational Psychology. 2000, 25 (1), 54-67;

35. Cooper K.H. The Aerobics Program for Total Well-Being. New York: Bantam Books. 1982;

36. Atkinson G., Reilly T. Circadian variation in sports performance. Sports Medicine. 1996, 21, 292-312;

37. Johnson J.H., Siegel D.S. Effects of association and dissociation on effort perception. Journal of Sports Behavior. 1992, 15, 119-129;

38. Karageorghis C.I., Terry P.C. The magic of music in movement. Sport and Medicine Today. 2001, 5, 38-41;

39. Rejeski W.J., Best D., Griffith P., Kenney E. Sex-role orientation and the responses of men to exercise stress. Research Quarterly. 1987, 58, 260-264. 
dr n. o kult. fiz. Stefan Szczepan

Akademia Wychowania Fizycznego we Wrocławiu

Zakład Teorii i Metodyki Pływania

al. I.J. Paderewski 35

51-612 Wrocław, Poland

tel: 713473404

fax: 713473450

e-mail: stefan.szczepan@awf.wroc.pl 